\title{
Smoking and ulcer perforation
}

\author{
C Svanes, J A Søreide, A Skarstein, B T Fevang, P Bakke, S E Vollset, K Svanes, O Søreide
}

Department of

Surgery, Haukeland University Hospital, Bergen

C Svanes

B T Fevang

K Svanes

Department of Surgery, Rogaland

Hospital, Stavanger J A Søreide

Department of Surgery, Haraldsplass University Hospital, Bergen

A Skarstein

Department of Thoracic Medicine, Haukeland University Hospital, Bergen P Bakke

Section for Medical Informatics and

Statistics, University of Bergen

S E Vollset

National Hospital, University of Oslo, Norway

O Søreide

Correspondence to: Dr C Svanes, Department of Thoracic Medicine,

University of Bergen,

5021 Haukeland Hospital, Norway.

Accepted for publication 10 March 1997

\begin{abstract}
Background-The use of ulcerogenic drugs is the only well documented risk factor for peptic ulcer perforation, but accounts for only a quarter of the events. Smoking is a well known risk factor for uncomplicated ulcer disease, and patients with ulcer bleeding have increased death rates from smoking related disorders.

Aim-To assess the role of smoking in ulcer perforation.

Subjects-A total of 168 consecutive patients with gastroduodenal ulcer perforation and 4469 control subjects from a population based health survey.

Methods-The association between ulcer perforation and smoking habits was analysed by logistic regression while adjusting for age and sex.

Results-Current smoking increased the risk for ulcer perforation $\mathbf{1 0 - f o l d}$ in the age group 15-74 years (OR 9.7, 95\% CI 5.9 to 15.8) and there was a highly significant dose-response relationship $(p<0.001)$. The results were similar in men (OR 9.3, 95\% CI 4.9 to 17) and women (OR 11.6, 95\% CI 5.3 to 25 ), and for gastric (OR $10.5,95 \%$ CI 4.5 to 25 ) and duodenal (OR 8.6, 95\% CI 4.9 to 15.4 ) ulcer perforation. No increase in risk was found in previous smokers (OR $0.8,95 \%$ CI 0.2 to 2.2 ).
\end{abstract}

Conclusion-Our findings suggest that smoking is a causal factor for ulcer perforation and accounts for a major part of ulcer perforations in the population aged less than 75 years.

(Gut 1997; 41: 177-180)

Keywords: peptic ulcer perforation; gastric ulcer; duodenal ulcer; smoking; NSAID; risk factor

The aetiology of the majority of ulcer perforations is not known. Current use of nonsteroidal anti-inflammatory drugs (NSAIDs) has been shown to increase the risk for ulcer perforation 6-8 times, and seems to account for about a quarter of the events. ${ }^{12}$ The role of Helicobacter pylori infection in ulcer perforation is uncertain. In a study of patients with acute perforated duodenal ulcer the infection was as common among patients as among hospital controls. $^{3}$ However, smoking prevalences of $84 \%$ and $86 \%$ have been reported among patients with duodenal ulcer perforation, ${ }^{3}{ }^{4}$ and smokers have a threefold higher mortality from peptic ulcer than non-smokers. ${ }^{5}$ The purpose of the present study was to assess the role of cigarette smoking in ulcer perforation.

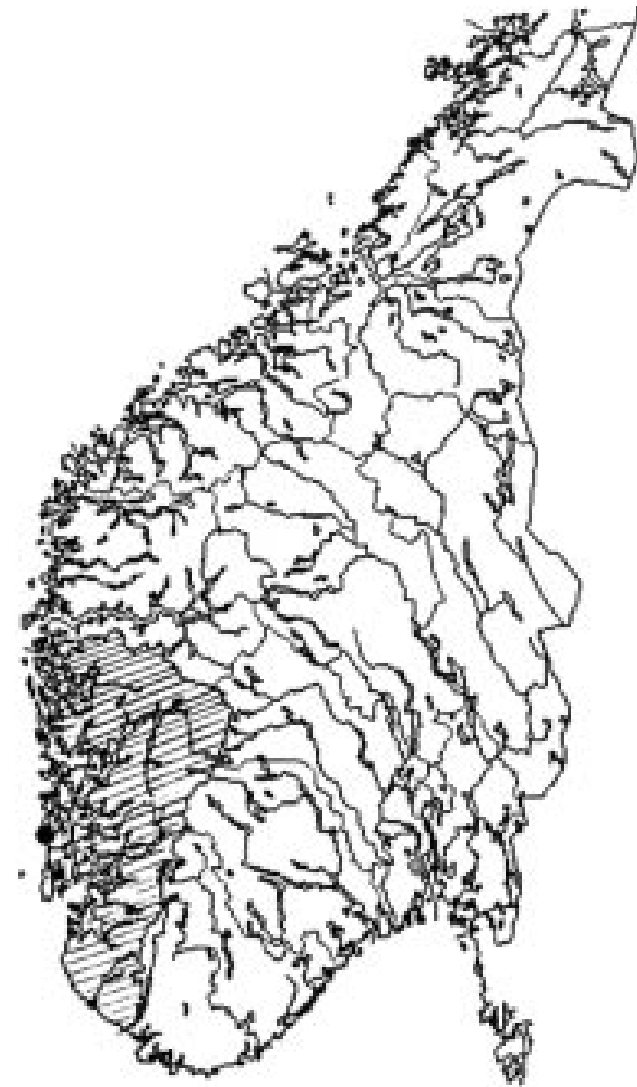

Figure 1: $\quad$ Shaded areas are Hordaland and Rogaland counties in western Norway.

\section{Methods}

PATIENTS

One hundred and seventy five consecutive patients with ulcer perforation admitted to three surgical departments in western Norway between July 1987 and June 1991 were included. The diagnosis was confirmed by operation (170 patients) or by necropsy (five patients). Structured interviews were performed by the authors (CS, JAS, AS, and BTS). One hundred and thirty eight patients $(79 \%)$ were successfully interviewed in hospital while 22 patients $(13 \%)$ were interviewed by telephone after discharge. Information on smoking habits was ascertained from relatives for eight of 15 patients who co-operated poorly (13, who all eventually died, due to poor general condition; two due to mental disturbances). Data on smoking habits were therefore available for 168 out of 175 patients (96\%). The patients were asked whether they smoked at the time of perforation. Patients answering "yes" $(n=107)$ were asked how many cigarettes, pipes, and/or cigars they smoked daily. A total of 102 patients reported daily cigarette smoking, seven patients smoked only 
TABLE 1 Previous medical history and use of drugs and alcohol in 168 patients with perforated peptic ulcer in western Norway 1987-1991

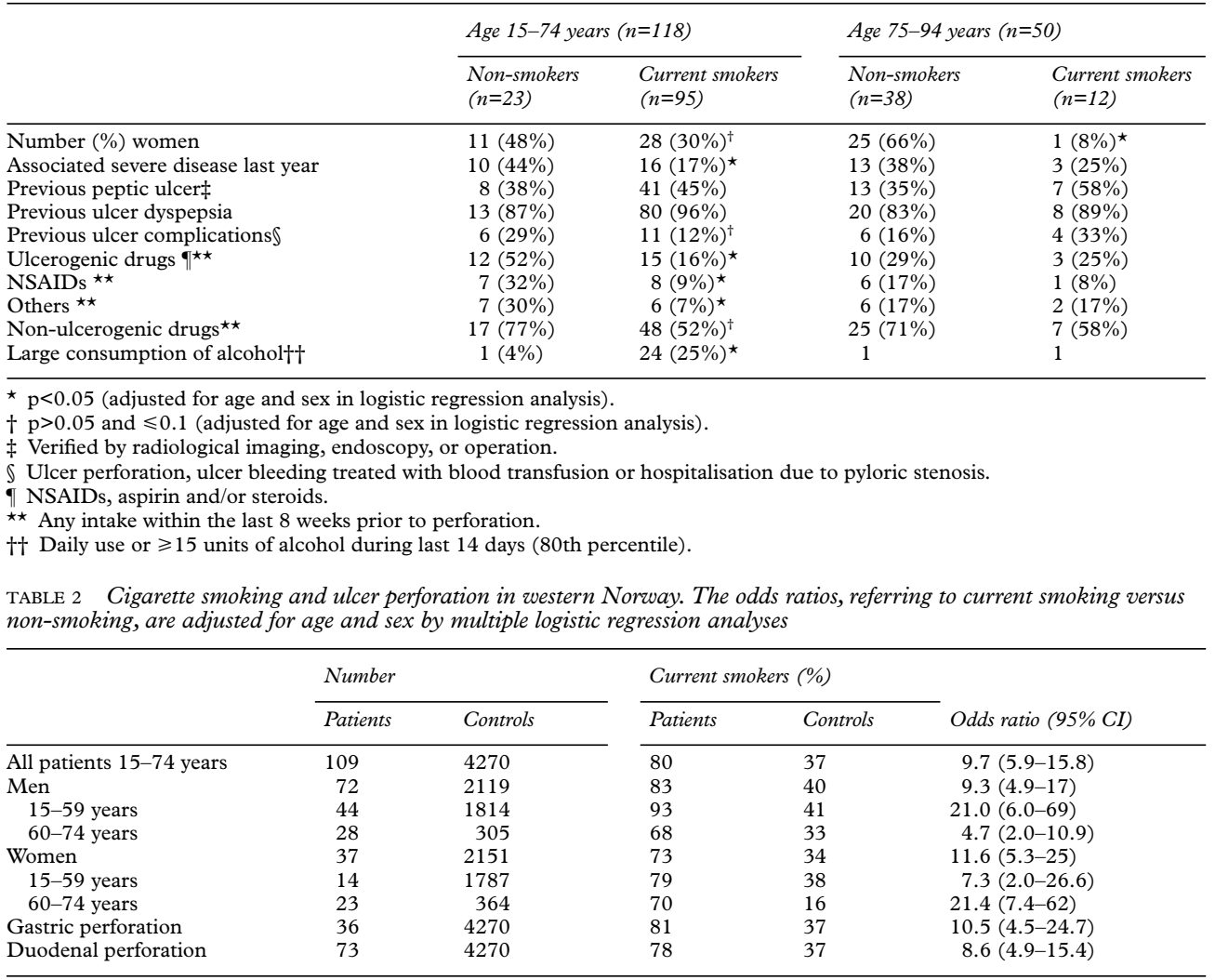

a pipe or cigars. Patients answering "no" were asked whether they had ever smoked and, if "yes" $(n=18)$, when they stopped smoking. Information on ulcer site was obtained from operation records. The perforations were classified as duodenal (including the pyloric orifice) or gastric (including the praepyloric area).

CONTROLS

Patients were retrospectively compared with participants in a population-based health survey conducted in Hordaland County, Norway in $1985 .{ }^{6}$ A postal questionnaire was sent to a random sample of 4992 persons aged 15-73 years, of whom $90 \%$ responded. The control subjects were asked whether they smoked cigarettes daily at present, how many cigarettes they smoked daily, and whether they had smoked before. ${ }^{6}$ Hordaland County includes the catchment area of two of the hospitals recruiting patients, while the third hospital was located in the neighbouring county of Rogaland (fig 1).

DEFINITIONS OF SMOKING HABITS

Current smokers were defined as persons who smoked daily at the time of perforation or at the time of the population survey. Ex-smokers were persons who had smoked daily and had given it up, while never-smokers were persons who had never smoked daily. Non-smokers were persons who did not smoke daily at the time of the perforation/survey, including ex-smokers and never-smokers. In analyses comparing patients and controls, those who smoked only a pipe or cigars were excluded.

\section{STATISTICAL METHODS}

The relation of smoking habits to disease status, with adjustment for age (five year age groups) and sex, was studied using multiple logistic regression analysis. For trend analysis smoking was coded as: 1 (never-smoker), 2 (ex-smoker), 3 (1-9 cigarettes daily), 4 (10-19 cigarettes daily), and $5(20+$ cigarettes daily). The odds ratios approximated relative risks since ulcer perforation is a rare disease. Population attributable risk (PAR\%) was calculated as follows: ${ }^{7}$

$$
\mathrm{PAR} \%=\left(\mathrm{P}_{\mathrm{e}}\right)(\mathrm{RR}-1) /\left(\left(\mathrm{P}_{\mathrm{e}}\right)(\mathrm{RR}-1)+1\right) \times 100
$$

where $\mathrm{P}_{\mathrm{e}}$ is the proportion of smokers in the population and $R R$ the relative risk of having an ulcer perforation.

\section{Results}

Among the patients, $80 \%$ in the age group 15-74 years were current smokers, while in the older subjects the smoking rate was $24 \%$. Patients who were smokers suffered from other severe diseases more rarely and used NSAIDs or other ulcerogenic drugs less often (table 1). On the other hand, smokers more often had a high alcohol consumption. Thirteen patients considered to have alcohol problems were all current smokers. There were no significant differences in previous ulcer history. 
TABLE 3 Ulcer perforation and increasing levels of cigarette smoking in the age group. 15-74 years in western Norway. The odds ratios are adjusted for age and sex by multiple logistic regression analyses

\begin{tabular}{lccc}
\hline & Patients & Controls & Odds ratio (95\% CI) \\
\hline Never smoked & $14(13 \%)$ & $1819(42 \%)$ & 1 \\
Ex smokers & $8(7 \%)$ & $882(21 \%)$ & $0.8(0.2-2.2)$ \\
$1-9$ cigarettes daily & $17(16 \%)$ & $321(7 \%)$ & $7.3(4.0-18.1)$ \\
$10-19$ cigarettes daily & $44(40 \%)$ & $880(21 \%)$ & $8.7(5.5-14.4)$ \\
$\geqslant 20$ cigarettes daily & $26(24 \%)$ & $368(9 \%)$ & $11.2(6.3-27.5)$ \\
Total & $109(100 \%)$ & $4270(100 \%)$ & \\
\hline
\end{tabular}

In the general population aged $15-74$ years $37 \%$ were daily cigarette smokers compared with $80 \%$ among patients (table 2). Adjusting for differences according to age and sex, ulcer perforation was estimated to be 9.7 times more common in daily cigarette smokers than in non-smokers (95\% CI 5.9 to 15.8) (table 2). The increase in risk was similar for men and women, and for gastric and duodenal ulcer perforation. According to these models, it was estimated that $76 \%$ (95\% CI 64 to 85$)$ of ulcer perforations in the population aged 15-74 years could be attributed to daily cigarette smoking. The population attributable risks were similar for men $(77 \%)$ and women $(78 \%)$.

The risk for ulcer perforation increased with the number of cigarettes smoked daily (table $3)$, with a highly significant trend $(\mathrm{p}<0.001)$. No association was found with former smoking. In the age group 15-74 years there were only $13 \%$ never-smokers among patients compared with $42 \%$ in the general population.

In patients aged 75 years or older smoking was not common and smoking habits differed markedly between the sexes. There was only one current smoker (4\%) among the female patients in this age group, and 23 of the 26 women $(88 \%)$ had never smoked. In the male patients 11 out of $24(46 \%)$ were current smokers. A population study of men in Hordaland in 1990 reported $23 \%$ current smokers in this age group, ${ }^{8}$ so an association between smoking and ulcer perforation is also suggested among men in this age group (OR 2.6, 95\% CI 1.2 to 5.8$)$. However, it was estimated that only $28 \%$ (95\% CI 4 to 52 ) of the ulcer perforations in men aged 75 years or more could be attributed to smoking.

\section{Discussion}

The present study suggests that most ulcer perforations among persons aged less than 75 years are caused by smoking. We found a very strong association between current cigarette smoking and ulcer perforation, the strength of the association was consistent between subgroups, and there was a significant doseresponse relationship.

The results of the present study are subject to many potential biases. The usual problem of bias in the selection of the controls could, however, be kept to a minimum as data from a population survey with a high response rate were used for control purposes. Bias related to selection of cases also seems unlikely. Ulcer perforation is a disease where all patients are admitted to hospital because of the severity of symptoms and the relatively long time lag between perforation and death. The diagnosis can be verified by operation or necropsy.

Different methods of data collection for cases and controls is a potential problem in this study. The main results $\left(\mathrm{OR}_{15-74 \text { years }} 9.7 ; \mathrm{OR}_{\text {men }}\right.$ 9.3; $\left.\mathrm{OR}_{\text {women }} 11.6\right)$ were thus cross-checked using information from national interview surveys. $^{9}$ This gave strikingly similar results $\left(\mathrm{OR}_{15-74 \text { years }}\right.$ 9.3; $\mathrm{OR}_{\text {men }}$ 9.3; $\mathrm{OR}_{\text {women }}$ 9.2). A community study in England suggested that self-reported smoking prevalences in population studies were underestimated by $3 \% .{ }^{10}$ Given that smoking in the present study was $3 \%$ underestimated among controls and 3\% overestimated among patients, the crude odds ratio (not adjusted for age and sex) would decrease from 6.8 to 5.0 , which still leaves a very strong association between ulcer perforation and smoking.

The population survey used as the control population was conducted in 1985, which is 2-6 years before the case collection. During this period of time smoking prevalences in Norway have decreased among men and remained unchanged among women. ${ }^{9}$ Thus, this time difference could lead to an underestimation of the association between smoking and ulcer perforation. The data on male patients were re-analysed using control data from a questionnaire survey of Hordaland men conducted in $1990,{ }^{8}$ which gave an age-adjusted odds ratio of 9.9 .

Theoretically, smoking could be a marker for other differences between cases and controls. Among the patients, $52 \%$ of the non-smokers had used ulcerogenic drugs and $48 \%$ had other severe diseases. In patients who were smokers other risk factors were rarely identified except for a higher use of alcohol. Such data were not available for the control population, so the influence of these factors on the association between smoking and ulcer perforation could not be adjusted for. Based on the information on patients, one might suspect that adjustment for use of NSAIDs would have resulted in an even stronger association between smoking and ulcer perforation.

The association between ulcer perforation and smoking seems biologically plausible. Smoking is known to have several adverse effects on the upper gastrointestinal tract. ${ }^{11}$ Of particular interest for ulcer perforation is the finding that smoking causes immediate vasoconstriction in the mucosa. ${ }^{12}$ Ischaemia reduces mucosal resistance ${ }^{13}$ against, for instance, the action of acid and may thus contribute to ulcer perforation. This mechanism could explain why we observe an increased risk in current smokers but not in former smokers.

In elderly persons smoking seemed to be of less importance than in the younger age group. A previous study showed higher excess mortality after ulcer perforation in persons born after $1910 .{ }^{14}$ These findings may suggest a shift in the aetiology of ulcer perforation over time, with smoking having a more predominant role in younger generations.

Tobacco smoking is a well known risk factor for uncomplicated peptic ulcer. ${ }^{15-17}$ Smokers 
have an increased risk for dying from peptic ulcer disease ${ }^{4}$ and increased death rates from smoking-related disorders have been reported in patients with ulcer bleeding. ${ }^{18}$ The present study strongly suggests that most ulcer perforations are related to smoking. The focus on NSAIDs in the aetiology of peptic ulcer disease seems appropriate as the complications relating to NSAID usage are iatrogenic. However, the findings of this study suggest that the incidence of ulcer perforation can only be markedly reduced, on a population basis, by smoking prevention.

1 Rodriguez LAG, Jick H. Risk of upper gastrointestinal bleeding and perforation associated with individual nonsteroidal anti-inflammatory drugs. Lancet 1994; 343: 769 72 .

2 Henry D, Dobson A, Turner C. Variability in the risk of major gastrointestinal complications from non-steroidal anti-inflammatory drugs. Gastroenterology 1993; 105: 1078-88.

3 Reinbach DH, Cruickshank G, McColl KEL. Acute perforated duodenal ulcer is not associated with Helicobacter pylori infection. Gut 1993; 34: 1344-7.

4 Smedley F, Hickish T, Taube M, Yale C, Leach R, Wastell C. Perforated duodenal ulcer and cigarette smoking. $\mathcal{F} R$ Soc Med 1988; 81: 92-4.

5 Doll R, Peto R, Wheathly K, Gray R, Sutherland I Mortality in relation to smoking: 40 years' observations on male British doctors. BMF 1994; 309: 901-11.

6 Bakke P, Gulsvik A, Eide GE, Hanoa R. Smoking habits and lifetime occupational exposure to gases or dusts, including asbestos and quartz, in a Norwegian community. Scand $\mathscr{f}$ Work Environ Health 1990; 16: 195-202.
7 Hennekens $\mathrm{CH}$, Buring JE. Epidemiology in medicine. Boston/Toronto: Little, Brown, 1987.

8 Humerfelt S, Gulsvik A, Skjærven R, Nilssen S, Kvåle G, Sulheim $\mathrm{O}$, et al. Decline in $\mathrm{FEV}_{1}$ and airflow limitation related to occupational exposures in men of an urban community. Eur Respir f 1993; 6: 1095-103.

9 Rønneberg A, Lund KE, Hafstad A. Lifetime smoking habits among Norwegian men and women born between 1890 and 1974. Int f Epidemiol 1994; 23: 267-76.

10 Lee PN. Passive smoking and lung cancer association: a result of bias? Hum Toxicol 1987; 6: 517-24.

11 Eastwood GL. The role of smoking in peptic ulcer disease. $f$ Clin Gastroentrol 1988; 10 (suppl 1): S19-23.

12 Iwao T, Toyonaga A, Ikegami M, Oho K, Sumino M, Sakaki $\mathrm{M}$, et al. Gastric mucosal blood flow after smoking in healthy human beings assessed by laser Doppler flowmetry. Gastrointest Endosc 1993; 39: 400-3.

13 Sørbye H, Svanes K. The role of blood flow in gastric mucosal defence, damage and healing. Dig Dis 1994; 12: 305-17.

14 Svanes C, Lie SA, Lie RT, Kvåle G, Svanes K, Søreide O. Survival after peptic ulcer perforation - a time trend analysis. f Clin Epidemiol 1996; 49: 1363-71.

15 Kato I, Nomura AMY, Stemmermann GN, Chyou PH. A prospective study of gastric and duodenal ulcer and its relation to smoking, alcohol and diet. Am f Epidemiol 1992; 135: 521-30.

16 Stemmermann GN, Marcus EB, Buist AS, MacLean CJ. Relative impact of smoking and reduced pulmonary function on peptic ulcer risk. A prospective study of Japanese men in Hawaii. Gastroenterology 1989; 96: $1419-24$.

17 Kurata JH, Nogawa AN, Abbey DE, Petersen F. A prospective study of risk for peptic ulcer disease in Seventh-day Adventists. Gastroenterology 1992; 102: 902-9.

18 Hudson N, Faulkner G, Smith SJ, Langman MJS, Hawkey CJ, Logan RFA. Late mortality in elderly patients surviving acute peptic ulcer bleeding. Gut 1995; 37: 177-81. 